\title{
A Histórica Multiplicidade da Psicologia Social
}

\author{
Maria Fernanda Costa Waeny* \\ Universidade Ibirapuera, São Paulo, SP, Brasil \\ ORCID: https://orcid.org/0000-0002-7220-6281 \\ Cibele Mariano Vaz de Macedo** \\ Universidade Ibirapuera, São Paulo, SP, Brasil \\ ORCID: https://orcid.org/0000-0002-4130-2115
}

\begin{abstract}
RESUMO
O texto relata os resultados de pesquisa por títulos em psicologia social anteriores a 1908 disponíveis em fontes digitais. Esta pesquisa retornou autores pouco citados, como Philarète Chasles e Paul Lapie; também possibilitou identificar que os conhecidos títulos de Gabriel Tarde e de Charles Ellwood são, de fato, uma seleção de artigos já publicados anteriormente; portanto, apenas os livros de Chasles e de Lapie são publicações originais. Em uma segunda etapa da pesquisa Chasles e Lapieforam objeto de levantamento bibliográfico; investigando menções a estes autores, foram localizados artigos de pesquisadores em história da psicologia social. O conjunto de dados obtidos a partir desta coleta em fontes primárias e a análise de alguns conceitos e proposições em psicologia social complementam o objeto deste artigo. Por fim, conclui-se que as novas metodologias digitais e o acesso a acervos digitais contribuem para identificar fontes primárias inéditas, as quais propiciam novas perspectivas historiográficas e a investigação de concepções vigentes no período tratado, mas pouco conhecidas em relação à multiplicidade da psicologia social; investigações como essa podem ampliar a perspectiva sobre o processo de constituição da psicologia social, renovar a pesquisa sobre a disciplina e a narrativa que se tem construído a seu respeito.
\end{abstract}

Palavras-chave: história da psicologia social, Philarète Chasles, Paul Lapie, Gabriel Tarde, humanidades digitais.

\section{The Historical Multiplicity of Social Psychology}

\begin{abstract}
The text reports search results for titles in social psychology before 1908 available in digital sources. This research returned little cited authors such as Philarète Chasles and Paul Lapie; it also made it possible to identify that the well-known titles of Gabriel Tarde and Charles Ellwood are, in fact, a selection of articles previously published; therefore, only the books of Chasles and Lapie are original publications. In a second stage of the research Chasles and Lapie were object of bibliographic research; investigating mentions to these authors, articles from researchers in history of social psychology were founded. The dataset obtained from this collection in primary sources and the analysis of some concepts and propositions in social
\end{abstract}


psychology complement the object of this article. Finally, it is concluded that new digital methodologies and access to digital collections contribute to identify unpublished primary sources, which provide new historiographic perspectives and the investigation of conceptions prevailing in the period treated, but little known in relation to the multiplicity of social psychology; investigations like this can expand perspective about the process of social psychology constitution, renew research on this discipline and the narrative that has been built about it.

Keywords: history of social psychology, Philarète Chasles, Paul Lapie, Gabriel Tarde, digital humanities.

\section{La Multiplicidad Histórica de la Psicología Social}

\section{RESUMEN}

El texto informa los resultados de búsqueda de títulos en psicología social anteriores a 1908 disponibles en fuentes digitales. Esta investigación recuperó autores poco citados como Philarète Chasles y Paul Lapie; también posibilitó identificar que los títulos conocidos de Gabriel Tarde y Charles Ellwood son, de hecho, una selección de artículos publicados previamente; por lo tanto, solo los libros de Chasles y Lapie son publicaciones originales. En una segunda etapa de la investigación, Chasles y Lapie fueron objeto de una búsqueda bibliográfica; buscando menciones de estos autores, se encontraron artículos de investigadores en historia de la psicología social. El conjunto de datos obtenidos de esta búsqueda en fuentes primarias y el análisis de algunos conceptos y proposiciones en psicología social complementan el objeto de este artículo. Finalmente, se concluye que las nuevas metodologías digitales y el acceso a colecciones digitales contribuyen a identificar fuentes primarias inéditas, que proporcionan nuevas perspectivas historiográficas y la investigación de concepciones vigentes en el período, pero poco conocidas con relación a la multiplicidad de la psicología social; tales investigaciones pueden ampliar la perspectiva sobre el proceso de constitución de la psicología social, renovar la investigación sobre la disciplina y la narrativa que se ha construido sobre ella.

Palabras clave: historia de la psicología social, Philarète Chasles, Paul Lapie, Gabriel Tarde, humanidades digitales.

A investigação histórica teve seu horizonte ampliado com a pesquisa em fontes digitais, processo que pode ocorrer também com as pesquisas em psicologia social. Entendese que a pesquisa sobre a história da psicologia social em fontes primárias digitais é mais um instrumento de consulta a publicações antigas ou de difícil acesso, podendo ampliar e atualizar a revisão bibliográfica, facilitar a busca de títulos inéditos ou, ainda, identificar argumentos e proposições a partir dos próprios autores. 
Sem adentrar nas questões de método relativas à multiplicidade de histórias e de psicologias sociais (Alvaro \& Garrido, 2003; Cordeiro, 2013; Farr, 1996) e ao uso da internet em pesquisas históricas sobre este tema (Almeida, 2011; Araújo, 2014), formula-se a seguinte pergunta: os primórdios da psicologia social e seus conteúdos, tal como apresentados pelos livros e manuais tradicionais, serão confirmados pela consulta a acervos e fontes digitais disponíveis online? Retomar a pergunta sobre a multiplicidade e os conteúdos preferenciais da psicologia social ao longo de seu percurso, com base nesta ferramenta de pesquisa, pode alargar o âmbito de análise histórica e aprofundar o conhecimento a respeito desta disciplina . Espera-se que a análise do conjunto de dados obtidos em fontes primárias e acervos online aqui apresentado possa fornecer uma perspectiva mais abrangente e contextualizada sobre a multiplicidade da psicologia social e sua história. A perspectiva historiográfica que orienta este texto se ampara na história-problema da Escola dos Annales (Barros, 2018).

A pesquisa inicial foi realizada no site da Biblioteca Nacional da França (http://gallica.bnf.fr), com o descritor "psychologie sociale"; ao resultado obtido aplicou-se o filtro "livros", selecionando os títulos com "psychologie sociale" anteriores a 1908, data tradicionalmente relacionada aos textos pioneiros de Ross (1908) e Mc Dougall (1908) (Alvaro \& Garrido, 2003; Farr, 1996). Em seguida fez-se nova pesquisa na internet, desta vez buscando autores de livros de psicologia social anteriores a 1908. Após esta primeira consulta procedeu-se à pesquisa na internet por autores de títulos em psicologia social em acervos digitais (https://archive.org/; https://www.jstor.org/); os quais, por sua vez, retornaram artigos sobre a história da psicologia social. O principal motivo para este procedimento foi localizar autores anteriores a 1908, consultar as fontes primárias, ler os próprios autores, identificar as respectivas concepções de psicologia social e sua abrangência; ampliar os marcos históricos tradicionais e a própria concepção da multiplicidade da psicologia social. Considera-se que a predominância da psicologia social europeia decorre do método de coleta, da disponibilidade de arquivos digitais e da importância dessa região para o conhecimento produzido à época, ou seja, anterior a 1908 .

\section{Primeiros Títulos em Psicologia Social}

Os escritos sobre história da psicologia social em geral citam os já tradicionais pioneiros, Ross (1908) e Mc Dougall (1908), como o fazem Alvaro e Garrido (2003), Consolim (2007), Franzoi (2007), Farr (1996), Ferreira (2011) ou Goethals (2003). Mas também há textos que abordam autores anteriores ao clássico marco de 1908: Apfelbaum 
(1981) avalia que Chasles (1875) escreveu sobre psicologia social antes dessa área adquirir especificidade e explica porque Lapie (1898) subintitulou seu livro como psicologia social. Bomfim $(2003$, 2004) identifica os primórdios de um pensamento psicossocial em Chasles (1875). Lubek e Apfelbaum (1981) examinam as tentativas de se desenvolver uma psicologia social no período 1875 e 1914. Cada um desses autores aborda diferentes perspectivas relativas ao surgimento da psicologia social; para este artigo, porém, a pergunta é sobre a multiciplicadade da psicologia social no período anterior ao que se considera como sendo o de seu surgimento e posterior insticionalização.

Desta forma passam a figurar, ao lado dos tradicionais Ross (1908) e Mc Dougall (1908), antecessores reconhecidos (Le Bon, 1895; Sighele, 1892; Tarde, 1898; Wundt, 1900) e menos conhecidos (Baudouin, 1901; Bunge, 1903; Chasles, 1875; Drumont, 1889; Ellwood, 1899; Hamon, 1894, 1895; Lapie, 1898). Os antecessores, porém, nem sempre usaram expressamente o termo psicologia social em seus títulos. Sighele (1892) usou psicologia coletiva; Le Bon (1895), psicologia da multidão; Wundt (1900), psicologia dos povos; Drumont (1889), psicológico e social; Hamon $(1894,1895)$ tipificou seus livros como estudos de psicologia social; Baudouin (1901) acrescentou internacional; Bunge (1903), individual e social. Ou seja, dos títulos anteriores a 1908 somente Chasles (1875), Ellwood (1899 e 1901), Lapie (1898) e Tarde (1898) mencionaram expressamente psicologia social no título. Eles serão analisados a seguir.

\section{Análise Preliminar dos Primeiros Títulos em Psicologia Social Anteriores a 1908}

\section{Chasles e seu La Psychologie Sociale des Nouveaux Peuples. Oeuvre Phostume}

Jornalista e estudioso da literatura inglesa, Victor Euphémien Philarète Chasles (17981873) lecionou língua e literatura germânica e estrangeira no Collège de France entre 1841 e 1873; esta expertise explica a ênfase de sua bibliografia em literatura e crítica literária (Chasles, 1828 e 1851). O livro de psicologia social é sua última obra, o finalizou horas antes de falecer. Para ele, quem melhor percebe e expressa a evolução mais profunda e a mudança nos costumes são os escritores, conforme escreveu:

Eu quero estudar a fundo e também comparar, em suas variedades e essências, os diversos modos da vida atual e os graus de cultura, intelectual, física, moral dos povos da Europa civilizada e da América filha da Europa. Eu encontro os elementos desse 
estudo na produção literária universal dos últimos tempos (Chasles, 1875, p. 1, tradução nossa).

Para efetuar este estudo ele reuniu "conhecimentos novos, resultados e fatos importantes relativos à cultura moderna das almas e dos espíritos" (Chasles, 1875, p. 2). Todavia, para além da literatura e seus autores, Chasles (1875) pretendeu "conhecer as outras ações, as outras faculdades dos homens" (p.5). Ele avaliou que a rapidez dos tempos modernos difere da extrema lentidão dos tempos antigos; que Europa, América e Ásia ultrapassaram a civilização de outrora e estavam envolvidas por uma "cultura incessante de inteligência, de alma e de artes. Eis o que estudo" (p.4).

Chasles quis compreender a cultura moderna de seu tempo e suas características; ele fez isso a partir do que relatam os escritores de sua época. A literatura também foi abordada na psicologia social (Völkerpsychologie) de Wilhelm Wundt (1832-1920). Wundt, porém, investigou os processos psíquicos elementares (sensação, percepção, representação) e os produtos superiores do espírito (literatura) visando descobrir as "leis gerais da vida mental" (Araújo, 2009, p. 216). Chasles, por sua vez, quis compreender seu tempo e não explicitou intenção de formular uma teoria da vida mental. Foi nesta perspectiva que Chasles mencionou a psicologia social, no capítulo sobre o romancista Alexandre Dumas (pai ${ }^{1}$ ); escreveu Chasles:

Dumas também se gabava de ter respeitado a moralidade. Seus setecentos ou oitocentos volumes não têm o valor de dois livros perniciosos, indecentes ou imorais. Primeiro, ele escreveu oitocentos livros? Sim, e muito mais. Homens robustos fazem quinze milhas por dia, se habituam a isso e assim facilmente realizam a volta em torno do mundo. Dumas era, física e intelectualmente, o robusto por excelência; e esta transformação do escritor em artesão, do poeta em trabalhador, por sua vontade própria e pela [vontade] do público, é um dos signos mais notáveis da psicologia social atual na França. (Chasles, 1875, pp. 118, tradução nossa).

Observa-se que Chasles desqualificou a obra de Dumas; apesar da má qualidade e desprovida de valor literário, ele admitiu que essa literatura foi absorvida pela sociedade. Questionou Chasles (1875): "Por que a literatura de Dumas, frívola e sem rumo, tem tido tanto espaço?" (p.124); atribuiu como motivos a fadiga das revoluções, o cansaço das doutrinas absolutas, a sucessão de desastres, certa tendência literária do período, o aumento 
do número de leitores; mas ele também considerou que seria possível influenciar, senão impor, outro objetivo que o de divertir caso o novo público leitor tivesse algum ideal mais elevado, tal como uma “ideia religiosa ou amor à liberdade e ao país” (p. 124).

Chasles (1875) analisou o desenvolvimento do romance. Identificou transformações no autor(Dumasse tornou um escritor sem criatividade, em sua visão), no público leitor (a nova massa de leitores iletrados) e na própria sociedade. Embora não aprofunde as razões, estabeleceu correlação entre uma produção literária pouco relevante e sem criatividade e um público leitor igualmente inferior. Este tripé escritor-público-sociedade compõe sua psicologia social.

A concepção de psicologia social em Chasles (1875), portanto, abrange o estudo do homem moderno. Para isto, enumera eventos que afetavam o conjunto daquela sociedade, cita possíveis tendências em vigor, considera que a relação indivíduo-sociedade é dinâmica e que as mudanças na sociedade resultam de diferentes determinações sociais.

\section{Lapie e seu Les Civilisations Tunisiennes: Musulmans, Israélites, Européens. Étude de Psychologie Sociale}

Filósofo e educador, Paul Lapie (1869-1927) contribuiu para a construção da escola republicana e laica e para a democratização da educação francesa (Cherkaoui, 1979; Terral, 2005). Morou em Túnis durante três anos, entre 1893 e 1896, e nesse período coletou dados para seu livro de psicologia social (Lapie, 1898). O texto se inicia falando do entorno - ao norte, uma salina que dá a "ilusão de um mar de gelo" (p. 1), de uma paisagem polar sob o sol da África - e da população de diferentes origens que habita Túnis. Ele completa o relato e anuncia seu objetivo:

esta paisagem é o símbolo de Túnis onde cem mil árabes, quarenta mil judeus, muitos europeus justapõem suas civilizações contraditórias. Entre a sociedade europeia e as sociedades indígenas, entre a sociedade muçulmana e sociedade judaica o contraste é tão violento como entre o polo e os trópicos. Expor as contradições que fazem da cidade um tipo de absurdo vivo; pesquisar como este absurdo pode se manter, como podem se associar esses elementos incompatíveis, tal é o objetivo deste trabalho (Lapie, 1898, pp.2, tradução nossa). 
Para Lapie (1898), as civilizações não se explicam pela raça e nem pelas religiões, pois estas são causas secundárias; elas se explicam pelos hábitos mentais de cada um desses povos, o que realmente importa é a alma de um povo; alma significa combinações originais de crenças e costumes, grupos de tendências comuns, não uma consciência coletiva e permanente; e os hábitos mentais que compõem as almas, por sua vez, podem ser modificados por influências étnicas ou religiosas. Apesar de mencionar termos como alma, hábitos mentais, crenças e costumes, Lapie considera que

a preponderância do princípio psicológico fornece um fio condutor no estudo das três civilizações tunisianas, de seus contrastes e de suas relações. Se a alma dos povos explica sua civilização, primeiro é preciso estudar a linguagem que traduz esta alma, em seguida suas diversas necessidades: a cada uma delas deve corresponder uma instituição (Lapie, 1898, pp.25, tradução nossa).

Lapie (1898) perguntou e buscou explicar a vida social, como convivem e se compreendem homens que habitam um espaço no qual se fala sete línguas diferentes. Ele explicou que, no âmbito social, prepondera o francês, mas no literário várias línguas subsistem; e embora a unidade da linguagem não produza a unanimidade, ela torna possível as relações sociais. De modo que somente após examinar as línguas faladas em Túnis ele considera que pode desenvolver temas como "a riqueza, a família, o Estado, a religião e a arte dos tunisianos" (p. 25).

Observa-se que a psicologia social de Lapie (1898) mescla sociologia e psicologia; contudo, para os temas sociológicos ele estabeleceu a preponderância do princípio psicológico como fio condutor. Seu objetivo foi duplo: compreender os contrastes e aproximações dos povos de Túnis e saber "porque as três sociedades puderam viver lado a lado no passado e pesquisar se elas poderão continuar a viver lado a lado no futuro" (Lapie, 1898, p. 282).

Lapie (1898) analisou a sociedade, portanto, a partir da perspectiva da alma dos povos e do convívio social dos diferentes povos que habitam a cidade de Tunis; explicou o social pelos hábitos mentais dos indivíduos; e considerou que estes, por outro lado, são modificados por diferentes influências como a étnica e religiosa. Trata-se, portanto, de analisar a relação indivíduo-sociedade a partir das características climáticas e geográficas da região, dos diferentes povos que habitam Túnis e dos contrastes que caracterizam essa cidade. Um dos objetivos explicitados pelo autor visa o futuro da própria cidade ou da convivência destes diferentes povos e seus costumes na cidade, porque, conhecendo os princípios e fundamentos 
desses povos e respectivos hábitos, pode-se analisar a viabilidade dessa convivência no futuro.

\section{Tarde e seu Études de Psychologie Sociale}

O jurista e sociólogo Gabriel Tarde publicou seu livro de psicologia social em 1898 (Tarde, 1898); trata-se de uma seleção de doze artigos já publicados e aqui republicados na seguinte sequência: Avant-propos [1898]; La sociologie [sem data]; Les deux éléments de la Sociologie [1894]; Le transformisme social [1895]; L'idée de l'organisme social [1896]; Criminalité et santé sociale [1895]; La criminalité professionnelle [1896]; La jeunesse criminelle [1897]; Souvenirs de transports judiciaires[1897]; La graphologie [1897]; Sympathie et synthèse [1897]; La sociologie de M. Giddings [sem data]; Crimes, délits, contraventions [1895].

No Prefácio, o autor avisa que:

A mais completa desordem, confesso, presidiu esta seleção, e eu teria que me desculpar por essa miscelânea, não fosse ela intencional, visando dissimular ou talvez para dar suporte a uma uniformidade em um ponto de vista geral que lhe é comum. Temo que depois de me repreender por ser muito bagunçado, o leitor não me censure no final por ser muito sistemático. Mas me é tão impossível conceber uma mente humana sem um sistema como um corpo humano sem uma espinha dorsal (Tarde, 1898, Avant-propos, tradução nossa).

Sobesta anunciada miscelânea, citada por Tarde (1898) no trecho acima, deveria emergir uma unidade que justificasse o título do livro. Observa-se que os temas tratados no livro remetem à sociologia e à criminalidade; o conteúdo dessa seleção deveria esclarecer como o autor convergiu sociologia e criminalidade em torno de estudos de psicologia social.

Os capítulos sobre a criminalidade abordam diferentes aspectos da temática. Tarde (1898) criticou Émile Durkhheime sua "maneira de conceber a criminalidade" (p. 137). Diferenciou dois significados dos delitos profissionais: um relativo ao número e tipo de infrações, geralmente descritos pelas estatísticas; o outro relativo às características de cada profissão e a moralidade que regula cada uma , o que "suscita maior interesse e profundidade" (p. 162). Avaliou que o aumento da criminalidade e do suicídio entre os jovens era uma questão complexa, analisando-a a partir de diferentes perspectivas. Defendeu a visita a cenas 
de crimes como meio eficaz para apurar responsabilidades penais; propôs manter a divisão em voga entre crimes, delitos e contravenções; e sugeriu simplificar as infrações e a criminalização de alguns tipos de reincidência. Tarde, porém, não se restringiu à estatística, aos dados penitenciários disponíveis, à tipologia infracional ou à prática jurídica; ele comparou a situação de sua época com o período anterior, bem como com o que ocorria na Inglaterra e também investigou o funcionamento de instituições escolares e conceitos correntes em um evidente esforço de ampliar sua compreensão sobre os determinantes da criminalidade.

Sobre a sociologia, Tarde (1898) afirmou que ela estava na moda, que sucedeu à psicologia e que seria uma psicologia coletiva; deveria comparar sociedades e seus aspectos, utilizando dados obtidos por "viajantes e historiadores, estatísticos e arqueólogos, naturalistas e psicólogos [que os] trouxeram de todos os lados para o uso dos sociólogos" (p.14). Investigou também as relações entre o individual e o geral, e entre os fatos sociais, em suas variações e repetições. Ao seu ver, a sociologia estudaria a repetição social de fatos psicológicos, isto é, a imitação. Identificar os fatos, atos e grupos sociais elementares, bem como seu caráter distintivo, sua repetição e combinação, permitiria formular leis da imitação. Por fim, em outros textos analisou criticamente conceitos e ideias vigentes (Le transformisme social; L'idée de l'organisme social; Sympathie et synthèse; La graphologie; La sociologie de M. Giddings) que de sua perspectiva eram pertinentes à psicologia social.

Além do título, a única menção de Tarde (1898) à psicologia social é no capítulo Os dois elementos da sociologia, texto originalmente apresentado ao $1^{\circ}$ Congresso Internacional de Sociologia, em 1894. Disse ele:

A sociologia pode ser concebida, e ela foi concebida, sucessivamente: $1^{\circ}$ como uma física social (os economistas, Auguste Comte); $2^{\circ}$ como uma biologia social (Spencer); $3^{\circ}$ como uma psicologia social. E cada uma dessas concepções tem seu lado plausível, se bem que apenas a terceira, a meu ver, seja tanto compreensiva como penetrante. Mas a pior noção que se pode fazer de nossa ciência é creio eu, concebêla, $4^{\circ}$ como uma ideologia social (Tarde, 1898, pp. 92-93, tradução nossa).

Neste breve histórico, a psicologia social aparece como a terceira etapa da sociologia. Segundo Tarde, excluindo a ideologia social, todas as outras concepções seriam plausíveis, mas apenas a psicologia social seria compreensiva e penetrante. Ele não define com precisão 
estes dois atributos, mas se espera que a psicologia social seja compreensiva e penetrante nos dois temas centrais do livro, a sociologia e a criminalidade.

\section{Ellwood e seu Some Prolegomenato Social Psychology}

O artigo do sociólogo Charles Abram Ellwood ( 1873-1946) Prolegomenato Social Psychology. The Need of the Study of Social Psychology (Ellwood, 1899) integra sua tese de doutorado em filosofia (Ellwood, 1901), defendida na Universidade de Chicago, em 1901;os capítulos originalmente foram "publicados como artigos no American Journal of Sociology" (Ellwood, 1901, p. iv). No texto The Need of the Study of Social Psychology, Ellwood (1899) afirmara que "a melhor maneira para se discutir o objeto da psicologia social é apontar a necessidade teórica de tal ciência” (p. 656); avaliara que parte da psicologia social foi abarcada pela ciência social; definira que seu objetivo seria propor a psicologia social como condição para um conhecimento social completo e que, para que este conhecimento fosse possível, seria preciso assumir que a sociedade é um fenômeno prioritariamente psíquico e, portanto, os processos psíquicos que caracterizam a vida do grupo são a mais importante condição para um conhecimento social completo. Escreveu ainda que se tratava de um apelo ao estudo da psicologia social, pois ela seria necessária à interpretação do processo social como um todo, e também para a economia, ciência política, ética, a crítica do falso (ou as crenças e valores transcendentais e/ou sem referência ao concreto) e a construção de programas sociais (Ellwood, 1899, p. 665).

Na tese, Ellwood (1901) aprofundou o artigo de 1899. No Prefácio, por exemplo, informou o caráter filosófico da tese; na sequência, citou motivos para a psicologia ter falhado na solução de problemas sociais porque desconsiderava a vida como processo; propôs o conceito de "mente social", alegando que esta noção inseriria a psicologia social no âmbito da moderna psicologia; criticou as proposições de Gabriel Tarde e James Mark Baldwin (18611934) sobre a imitação alegando que ambos fizeram do processo social algo à parte do processo da vida; defendeu que a unidade do social seria o fato fundamental da psicologia social, e também o que a tornaria prática e concreta. A crítica aos conceitos vigentes sobre a imitação, a proposição de uma noção como mente social e a aplicação prática da psicologia social demonstram o empenho de Ellwood $(1899,1901)$ em construir uma psicologia social, conceitual e teoricamente consistente. 


\section{Algumas Observações Sobre o Uso do Termo Psicologia Social em Textos do Período}

Menções à psicologia social no corpo de textos são ainda mais anteriores aos primeiros títulos analisados, conforme demonstram os exemplos a seguir. François Barrier, (1813-1870)cirurgião, professor e presidente da Sociedade Protetora da Infância de Paris, publicou Principes de sociologia em 1867; o livro divide-se em duas partes, Estudo do homem e Estudo da sociedade, antecedidas por uma Introdução. Para Barrier (1867), a sociabilidade seria uma das formas de atividade humana e serviria de base para a ciência social; o estudo do homem abarca apenas as faculdades superiores, e estas fazem do homem um ser passional, inteligente e artista; a reunião destes três aspectos sob o nome de sociabilidade caracteriza o objeto da psicologia social, e isto o direciona a "perguntar qual é a tarefa respectiva de cada um desses três atributos gerais" (p.56-57); ou seja, o objeto da psicologia social seriam as faculdades superiores do homem e a sociabilidade humana.

O filósofo Etiènne Vacherot (1809-1897), em La Science et la conscience (Vacherot, 1870), por sua vez, avaliou que sua época apresentaria as "obras de verdadeira ciência histórica" (p.109); isto seria assegurado pela aplicação do método científico e pelo conhecimento completo e aprofundado de textos e monumentos; antes dessa época, porém, "a história foi apenas um tipo de psicologia social, tendo por único objeto a alma dos indivíduos e dos povos" (p.109). Vacherot reconheceu os avanços de sua época e criticou a história e a psicologia social de outrora porque ambas teriam como mesmo objeto a alma (individual e coletiva); ao tecer sua crítica, porém, também mostrou o predomínio do laço entre história e alma, ou a alma de um povo, conforme estava presente nos estudos de psicologia social daquele período.

Joseph Tissot (1801-1876), em Th. Jouffroy: savie et sesécrits (Tissot, 1875), escreveu sobre o filósofo Théodore-Simon Jouffroy (1796-1842); as duas menções à psicologia social estão no item dedicado à moral (ou direito natural). Nas duas citações, porém, Tissot atribuiu a Jouffroy o termo psicologia social. Na primeira menção, Tissot (1875, p.116) escreveu que, em sua lição sobre o ceticismo, Jouffroy forneceu um dos melhores exemplos de psicologia social ou antropologia; na segunda Tissot (1875, p.123), relatou que Jouffroy fez "uma exposição muito boa, mas muito verdadeira, do fenômeno da psicologia social representando a passagem da ciência para o estado do senso comum" (p. 123). Em nossa interpretação, considerar como sendo "psicologia social" o pensamento de um autor que não a mencionou pode mostrar a crescente importância do termo e sua ainda frágil delimitação. 
A revista mensal Le livre (1881) noticiou, na seção de cursos, que "M. Caro vai estudar Psicologia Social; ele tratará da ação da sociedade sobre o indivíduo e de seu papel no desenvolvimento do homem intelectual e moral" (p.54). O trecho, porém, não especifica o local ou duração do curso. De qualquer forma o trecho contribui para caracterizar alguns aspectos sobre a psicologia social daquela época - no caso, a ação da sociedade sobre o indivíduo.

O verbete Suggestion (Larousse, 1878, p.1883-1885) aborda diferentes aspectos e conteúdos do termo (sugestionabilidade, sugestão hipnótica, sugestão mental, efeitos da sugestão, autossugestão e etc.). $\mathrm{O}$ autor, não identificado, cita a psicologia social em dois aspectos relativos à sugestão: um deles, devido à "captação do homem pelo homem” (p.1883), isto é, individualidades mais fortes que sugerem ideias aos demais; é uma ação do mais forte para o mais fraco explicitamente apoiada nas ideias do naturalista Charles Darwin (18091882) Outro aspecto, complementar ao anterior, refere-se à "a credibilidade do sujeito" (p. 1884). Sobre estes dois aspectos, captação do homem pelo homem e credibilidade do sujeito, escreveu o autor: "estas interessantes considerações de psicologia social mostram como são precárias as condições da liberdade humana e da espontaneidade do espírito, sem cessar acionadas por intervenções mais ou menos recentes e mais ou menos diretas das numerosas influências sugestivas" (Larousse, 1878, p. 1884). Psicologia social, neste caso, se referiria aos processos de dominância e credibilidade entre os indivíduos que são a base dos fenômenos da sugestão.

Os já citados livros de Hamon $(1894,1895)$ não têm psicologia social no título; na parte superior da folha de rosto de um desses livros vem impresso "Études de psychologie sociale" (Hamon, 1894), e no outro "Bibliothèque sociologique" (Hamon, 1895). Nos “Ètudes”, encontram-se os textos Psychologie Du militaire profissionnel (Hamon, 1894), em que o autor "tentou mostrar a influência da profissão sobre a mentalidade dos indivíduos que a exercem" (Hamos, 1895, Prefácio, p. IX), bem como Psychologie de l'anarchiste-socialiste (Hamon, 1895) em que o autor mostrou "que os adeptos de uma mesma doutrina filosófica possuem uma constituição psíquica comum" (Hamos, 1895, Prefácio, p. X). Apesar da ausência do termo no título parece haver algum tipo de complementaridade e/ou alternância entre psicologia e sociologia na definição daquilo que, para Hamon, seria a psicologia social.

O psiquiatra Édouard Toulouse (1865-1947) anunciou, na Revue de psychiatrie (Toulouse, 1900) por ele dirigida, a organização de uma "Biblioteca internacional de psicologia experimental normal e patológica"; seu objetivo seria "resumir os conhecimentos atuais em psicologia normal (sensações, funções intelectuais), comparada (psicologia social e 
animal), anormal (gênio) e mórbida (hipnotismo, loucura crime)" (p.219). O autor em seguida enumerou os temas de cada um dos cinquenta volumes e o respectivo responsável; para psicologia social e alguns outros temas, porém, não consta o nome do responsável pelo volume. A ausência de autoria dificulta qualquer inferência, mas merece destaque o fato de Toulouse unir psicologia social e psicologia animal em um volume de psicologia comparada.

O reconhecido psicólogo Alfred Binet (1857-1911), em 1908, se tornou "ardente defensor da psicologia social" (Apfelbaum, 1981, p.405); seu interesse inicial foi explicar os eventos que marcaram a sociedade francesa da época, pois "o estudo científico desses fenômenos sem dúvida ajudaria a elaborar estratégias sociais mais ajustadas" (p.405). Todavia, o interesse de Binet pelas questões sociais data de seu trabalho em escolas primárias, quando percebeu a importância dos determinantes sociais (como o papel da família e das condições físicas e sociais) no desempenho das crianças, bem como a importância das relações interpessoais (aluno-aluno, mestre-aluno). Tais fatores o teriam conduzido inicialmente a questões propriamente psicossociais e depois a uma teoria da influência social, que, segundo Apfelbaum (1981, p.405), Binet teria exposto em seu livro La suggestibilité, de 1900 .

Estas ocorrências exemplificam a variedade e diversidade de noções, conceitos e proposições em psicologia social anteriores a 1908; em outras palavras, relatam a multiplicidade que historicamente parece ter caracterizado a psicologia social desde seus primórdios. Noções como sociabilidade, ação da sociedade sobre o indivíduo, captação do homem pelo homem, credibilidade, elaboração de estratégias sociais, complementaridade e/ou alternância entre psicologia e sociologia, ou ainda análises históricas, bem poderiam se assemelhar a conceitos e concepções da psicologia social atual, ou a análises históricas sobre as origens e desenvolvimentos da psicologia social, não fosse a distância histórica e conceitual que nos separa dessa história, suas concepções e proposições.

\section{Considerações Finais}

Este texto amplia a pesquisa historiográfica em psicologia social por meio de consulta a fontes digitais e acervos digitalizados. Consulta de edições originais, artigos e demais fontes primárias, por sua vez, contribui para a historiografia da psicologia social, além de apresentar - ou reapresentar - autores pouco conhecidos, pode trazer à luz temas ainda inexplorados e aprofundar argumentos e interpretações de pesquisas anteriores. 
O livro de Chasles (1875), por exemplo, antecipa o tradicional surgimento de títulos em psicologia social de 1908 para 1875; se consideradas as menções anteriores à psicologia social, desde Barrier (1867) a Binet (1900), nota-se que o título de Chasles (1875) integra um contexto mais amplo de proposições e noções a respeito de uma psicologia social. Este mesmo argumento, o de um contexto propício para proposições em psicologia social, se aplica aos primeiros títulos de psicologia social: Tarde (1898), por exemplo, selecionou artigos já publicados e assim intitulou o volume; Lapie (1898), nesse mesmo contexto, comenta com Celestin Bouglé (conforme Apfelbaum, 1981, p. 401) que seria apropriado um livro com esse título; a tese de Ellwood (1901) reúne artigos publicados anteriormente.

Ou seja, é possível que à época houvesse um ambiente receptivo à demarcação de uma psicologia social, qualquer que fosse sua significação, amplitude teórica, proposições de ordem prática, ou embates institucionais, como os evidenciados por Consolim (2007). Assim, esta investigação inicial sobre a multiplicidade da psicologia social permite observar a ocorrência de uma dispersão também naquela época e levantar alguns questionamentos sobre se o marco histórico tradicionalmente aceito (1908) não reduziu essa diversidade; se, ao criarem-se as condições para o surgimento da disciplina, já foram excluídos determinados conteúdos; e se essa multiplicidade manteve-se à margem do (re)conhecimento institucional.

É possível que as relações entre psicologia social e sociologia fossem menos delimitadas ou, até mesmo o contrário, fossem estreitas. Em Ellwood, por exemplo, a psicologia social pôde ajudar na construção da sociologia; o livro de Augustin Hamon integra uma "Biblioteca sociológica" e o de Gabriel Tarde uma "Biblioteca sociológica internacional". Tarde (1898, p. 1) entende por "sociologia uma psicologia coletiva". Apfelbaum (1981) propõe a reticência de Durkheim no reconhecimento da Psicologia Social como um entre os prováveis motivos que dificultaram seu reconhecimento: para Durkheim, a ciência da vida coletiva poderia ser uma psicologia social, mas ela seria similar à Völker psychologie de Lazarus e Steinthal, ou seja, uma linguística geral e filologia comparada que até então não produzira resultados (p. 402). Pode-se considerar, então, que a reticência de Durkheim talvez fosse relativa principalmente aos riscos de identificar a psicologia social com a Völker psychologie, esta comprometendo a validade daquela devido, pelo menos aos olhos de Durkheim, à ausência de resultados da Völker psychologie alemã. Apfelbaum (1981) não menciona Wundt e se atém especificamente à proposta de Lazarus e Steinthal.

Retornar a acervos e arquivos, refazer a busca pelos primeiros títulos e menções, analisar aspectos das obras, pesquisar dados biográficos de autores que escreveram sobre psicologia social antes de 1908, demonstra que a variedade de temas abordados pela 
psicologia social foi também uma característica bem mais anterior ao que se supunha até então, e pelo menos ao longo do período estudado e referida a aspectos variados: literatura, contrastes e contradições das cidades e seus habitantes, ação entre os homens e respectivo domínio de uns sobre os outros, sugestão, relação indivíduo-sociedade, mente social, crítica à sociedade pela massificação do público leitor, mentalidade dos indivíduos, por exemplo, são temas e conteúdos abordados pelos autores de uma psicologia social ainda incipiente e estão na ordem do dia.

Retornar às fontes não esgota os autores e nem o tema, mas pode contribuir para aprofundar o conhecimento dos fatores envolvidos na constituição da psicologia social e para melhor contextualizar a psicologia social atual. Exemplo de contribuição a este respeito resulta da revisão bibliográfica para este artigo: textos de pesquisadores sobre os primeiros títulos em psicologia social anteriores a 1908 foram apresentados à primeira Conferência Internacional sobre história da psicologia social, ocorrida em 1991, no Institut de Recherches sur les Sociétés Contemporaines de Paris (http://www.persee.fr/doc/socco_11501944_1993_num_13_1_1094); os vinte e dois textos foram publicados em número especial da revista Canadian Psychology / Psychologie canadienne, assim dividida: Surl'histoire, La psychologie sociale danser apports avec la demande sociale e Constructions historiques de la psychologie sociale; analisá-los mais aprofundadamente, porém, ultrapassa o objetivo deste artigo.

Este artigo pesquisa menções e títulos à psicologia social anteriores a 1908; o retorno às fontes foi possível, primeiro, porque há uma data instituída, 1908; segundo, pelo acervo digital disponível na internet; por tais motivos ampliou-se a pesquisa sobre a psicologia social e sua história, numa tentativa de lhe acrescentar nuances possibilitadas pelo acesso direto aos escritos de autores que a ela se referiram antes de 1908.

As duas proposições, anterioridade da psicologia social no cenário intelectual e a diversidade da psicologia social no período abordado neste artigo, são inferências oriundas da coleta, manuseio, leitura e análise das obras e demais dados aqui apresentados. Para além de identificar um pioneiro (a exemplo de Auguste Comte, Wilhelm Wundt, Norman Triplett), a primeira menção ou título, ou o estabelecimento de uma disciplina, percebe-se a configuração de um novo cenário, de outra percepção e racionalidade, que resultou em novas formas de compreensão dos fenômenos e eventos: a relação entre o sujeito e as consequências de sua ação, por exemplo, passa a ser correlacionada à sociedade em que este sujeito vive e se constitui como tal; o convívio entre os indivíduos, por sua vez, caracteriza, determina e confere unidade a esta mesma sociedade; assim, uma dada sociedade passa a se caracterizar 
tanto pelos sujeitos que nela convivem - com seus hábitos e costumes -, como pelo conjunto da produção artística e intelectual, pelas suas instituições e conjunto de normas que regulam o funcionamento dessa sociedade. Vale lembrar que esta perspectiva da história-problema e da multiplicidade da psicologia social não são novas; assim como não é novo o método aqui utilizado; a novidade é apresentar menções e títulos em psicologia social anteriores a 1908 a partir das ideias e proposições que os próprios autores expuseram em seus textos de psicologia social, e no próprio cenário em que se constituíram estes conceitos, teorias, proposições e práticas, demonstrando a partir de fontes primárias a multiplicidade da psicologia social.

As avaliações, interpretações e propostas de análise sobre a psicologia social e sua história aqui expressadas representam a tentativa de relacionar o surgimento de menções a psicologia social ao contexto específico no qual emergiram noções e concepções psicossociais; este procedimento se justifica porque foi em torno destas noções e concepções psicossociais e/ou sociopsicológicas que se organizou e se construiu a história da psicologia social Que necessita ser melhor investigada.

\section{Referências}

Almeida, F. C. (2011). O historiador e as fontes digitais: Uma visão acerca da internet como fonte primária para pesquisas históricas. Aedos, 8(3), 9-30. Recuperado de http://seer.ufrgs.br/aedos/article/download/16776/11939

Alvaro, J. L. \& Garrido, A. (2003). Psicologia social: perspectivas psicológicas e sociológicas. São Paulo: Mc Graw-Hill.

Apfelbaum, E. (1981). Origines de la psychologie sociale en France: Développements souterrains et discipline méconnue. Revue française de sociologie, 22(3), 397-407. Recuperado de http://www.persee.fr/doc/rfsoc_0035-2969_1981_num_22_3_3437

Araújo, S. F. (2009). Uma visão panorâmica da psicologia científica de Wilhelm Wundt. ScientiaeStudia, 7(2), 209-20. doi:10.1590/S1678-31662009000200003

Araújo, Z. G. (2014). Ler, pesquisar e escrever história em tempos de internet: Desafios e possibilidades. Revista Tempo e Argumento, 6(12), 151-164. Recuperado de http://revistas.udesc.br/index.php/tempo/article/download/2175180306122014151/364 4

Barrier, F. (1867). Principes de sociologie. Paris: Noirot. Recuperado de http://gallica.bnf.fr/ark:/12148/bpt6k24226k 
Barros, J. C. A. (2018). Os historiadores e o tempo: A contribuição dos Annales. Cadernos de história, 19(30), 182-210. doi:10.5752/P.2237-8871.2018v19n30p182

Baudouin, M. (1901). Les femmes médicins: Étude de psychologie sociale internationale. Paris: Institut Intenational de Bibliographie. Recuperado de http://www2.biusante.parisdescartes.fr/livanc/?cote $=74197 \&$ do $=$ chapitre

Binet, A. (1900). La suggestibilité. Paris: Schleicher Frères.

Bomfim, E. M. (2003). Contribuições para a história da psicologia no Brasil. In A. M. JacóVilela, M. L. Rocha, D. Mancebo (Orgs.), Psicologia social: Relatos na América Latina (pp. 123-144). São Paulo: Casa do psicólogo.

Bomfim, E. M. (2004). Fragmentos psicossociais na histórica construção da identidade nacional. In M. Massimi, \& M. C. Guedes (Orgs.), História da psicologia no Brasil: Novos estudos (pp. 71-88). São Paulo: Educ/Cortez.

Bunge, C. O. (1903). Principes de psychologie individuelle et sociale (A. Dietrich, Trad.). Paris: Félix Alcan. Recuperado de http://gallica.bnf.fr/ark:/12148/bpt6k56842136

Chasles, P. (1828). Tableau de la marche et des progrès de la langue et de la littérature françaises, depuis le commencement du XVI e siècle jusqu'en 1610, discours qui a partagé le prix d'éloquence, décerné par l'Académie française, dans sa séance publique du 25 août 1828. Paris: Impr. de F. Didot.

Chasles, P. (1851). Études sur la littérature et les moeurs des Anglo-Américains au XIXe siècle. Paris: Amyot.

Chasles, P. (1875). La psychologie sociale des nouveaux peuples: Oeuvre phostume. Paris: Charpentier et Cie. Recuperado de http://gallica.bnf.fr/ark:/12148/bpt6k206493h

Cherkaoui, M. (1979). Les effets sociaux de l'école selon Paul Lapie. Revue française de sociologie, 20(1), 239-255. Recuperado de http://www.persee.fr/web/revues/home/prescript/article/rfsoc_00352969_1979_num_20_1_6682

Consolim, M. C. (2007). Crítica da razão acadêmica: Campo das ciências sociais "livres" e a psicologia social francesa no fim do século XIX (Tese de doutorado em Sociologia). Universidade de São Paulo, Faculdade de Filosofia, Letras e Ciências Humanas, São Paulo, SP, Brasil. http://www.teses.usp.br/teses/disponiveis/8/8132/tde-18032008150141/publico/TESE_MARCIA_CRISTINA_CONSOLIM.pdf 
Cordeiro, M. P. (2013). Psicologias sociais cientificista e crítica: Um debate que continua. Psicologia: Ciência e Profissão, 33(3), 716-729. doi:10.1590/S141498932013000300015

Drumont, É. A. (1889). La fin d'un monde: Étude psychologique et sociale. Paris: Albert Savine Éditeur. Recuperado de https://archive.org/stream/lafindunmondetu00drumgoog\#page/n13/mode/2up

Ellwood, C. A. (1899). Some prolegomena to social psychology. American journal of sociology, 4(5), 656-665. Recuperado de http://www.jstor.org/stable/2761588

Ellwood, C. A. (1901). Some prolegomena to social psychology. Chicago: University of Chicago Press. Recuperado de https://ia600201.us.archive.org/13/items/someprolegomena00ellwgoog/someprolegom ena00ellwgoog.pdf

Farr, R. (1996). As raízes da Psicologia Social moderna. Petrópolis: Vozes.

Franzoi, S. L. (2007). History of social psychology. In R. F. Baumeister \& K. D. Vohs (Orgs.), Encyclopedia of social psychology (pp. 431-439). Thousand Oaks: Sage. Recuperado de http://simbi.kemenag.go.id/pustaka/images/materibuku/encyclopediaof-social-psychology-volume-1.pdf

Ferreira, M. C. (2011). Breve história da moderna psicologia social. In C.V. Torres \& E. R. Neiva (Orgs.), Psicologia social: Principais temas e vertentes (pp. 13-30). Porto Alegre: Artmed. Recuperado de http://www.larpsi.com.br/media/mconnect_uploadfiles/c/a/cap_01pop.pdf

Goethals, G. R. (2003). A century of social psychology: Individuals, ideas and investigations. In M. A. Hogg \& J. Cooper (Orgs.), The sage handbook of social psychology (Vol. 1, pp. 3-23). London: Sage. Recuperado de http://public.psych.iastate.edu/caa/classes/Readings/Goethals03A\%20Centuary.pdf Hamon, A. F. A. (1894). Psychologie du militaire professionel. Bruxelles/Paris: Charles Rozez/A.L. Charles. Recuperado de https://ia600306.us.archive.org/25/items/psychologiedumi02hamogoog/psychologiedu mi02hamogoog.pdf

Hamon, A. F. A. (1895). Psychologie de l'anarchiste-socialiste. Paris: P.V. Stock. Recuperado de https://archive.org/stream/psychologiedela00hamogoog\#page/n6/mode/2up

Le Bon, G. (1895). Psychologie des foules. Paris: F. Alcan. 
Le Livre. Bibliographie moderne. (1881). Académie, sociétés, savantes, cours publics. Le Livre: revue mensuelle, 3, 53-57. Recuperado de http://gallica.bnf.fr/ark:/12148/bpt6k2091832

Lapie, P. (1898). Les civilisations tunisiennes: musulmans, israélites, européens: Étude de psychologie sociale. Paris: Ancienne Librairie Germer Baillière et Cie. Recuperado de http://gallica.bnf.fr/ark:/12148/bpt6k71505r

Larousse, P. (Éd.). (1878). Suggestion: Grand dictionnaire universel: Deuxième supplément (pp. 1883-1885). Paris: Administration du grand dictionnaire universel. Recuperado de http://gallica.bnf.fr/ark:/12148/bpt6k39804b

Lubek, I. (1993). Réflexions sur diverses psychologies sociales, leurs histoires et historiographies. Sociétés contemporaines, 13, 33-56. Recuperado de http://www.persee.fr/web/revues/home/prescript/article/socco_11501944_1993_num_13_1_1098

Lubek I. \& Apfelbaum, E. (1981). Histoire de psychologies sociales perdues: Le cas de Gabriel Tarde. Revue française de sociologie, 22(3), 361-395. Recuperado de http://www.persee.fr/web/revues/home/prescript/article/rfsoc_00352969_1981_num_22_3_3436

Mc Dougall, W. (1908). An introduction to social psychology. London: Methuen \& Co. Recuperado de https://archive.org/stream/introductiontoso020342mbp\#page/n0/mode/2up

Ross, E. A. (1908). Social psychology: An outline and source book. New York: Mac Millan Company.

Sighele, S. (1892). La foule criminelle: Essai de psychologie collective. Paris: Félix Alcan. (Obra original publicada em 1891)

Tarde, G. (1898). Études de psychologie sociale. Paris: V. Giard et E. Brière. Recuperado de http://gallica.bnf.fr/ark:/12148/bpt6k112962k

Terral, H. (2005). Paul Lapie (1869-1927): Universitaire et bâtisseur de l'école laïque. Carrefours de l'éducation, 1(19), 121-137. Recuperado de http://www.cairn.info/resume.php?ID_ARTICLE=CDLE_019_0121

Tissot, J. (1875). Th. Jouffroy: Sa vie et ses écrits. Paris: Didier. Recuperado de http://gallica.bnf.fr/ark:/12148/bpt6k64591777

Toulouse, É. (1900). Bibliothèque internationale de psychologie expérimentale normale et pathologique. Revue de Psychiatrie (Médicine mentale, neurologie, psychologie), 1, 
219-221. Paris: A. Maloine Éditeur. Recuperado de http://gallica.bnf.fr/ark:/12148/bpt6k64658538

Vacherot, É. (1870). La Science et la conscience. Paris: G. Baillière. Recuperado de http://gallica.bnf.fr/ark:/12148/bpt6k6535151f

Wundt, W. (1900). Völkerpsychologie: Eine Untersuchung der Entwicklungsgesetze von Sprache, Mythus und Sitte. Leipzig: Engelmann.

\section{Endereço para correspondência}

\section{Maria Fernanda Costa Waeny}

Rua Aparandé, 146 apto 23A, Vila Ipojuca, São Paulo - SP, Brasil. CEP 05054-070

Endereço eletrônico: fernandawaeny@ gmail.com

Cibele Mariano Vaz de Macedo

Rua Visconde de Porto Seguro, 1142 casa 2, Jardim dos Estados, São Paulo - SP, Brasil. CEP 04642-000

Endereço eletrônico: cibelevaz@gmail.com

Recebido em: 25/06/2019

Reformulado em: 02/10/2019

Aceito em: 08/10/2019

\section{Notas}

* Doutora em Psicologia Social (PUCSP). Docente do Mestrado em Psicologia da Universidade Ibirapuera. Pesquisa IgnaceMeyerson, psicologia histórica, riscos psicossociais.

** Doutora em Psicologia Social (UERJ). Docente do Mestrado em Psicologia na Universidade Ibirapuera-SP. Pesquisa processos de subjetivação e riscos psicossociais.

${ }^{1}$ Alexandre Dumas (pai) (1802-1870) foi um renomado escritor; livros como O conde de Monte Cristo e Os três mosqueteiros, ambos de 1844, lhe renderam dinheiro e fama. O filho, Alexandre Dumas (filho) (1824-1895) e também autor renomado, escreveu A dama das camélias (1848).

Este artigo de revista Estudos e Pesquisas em Psicologia é licenciado sob uma Licença Creative Commons Atribuição-Não Comercial 3.0 Não Adaptada. 